\section{Gerreral 急emarks}

\author{
ON THE
}

\section{PRACTICE OF MEDICINE.}

BY

P. M. LATHAM, M.D.

\section{XVII.}

Further Rernarks on Practical Experience. Experience comes from Experiments. Shewn in the Treatment of Acute Disease-as Pneumonia. And of Chronic Disease-as Pulmonary Consumption. How supervening Accidents make the Treatment of Diseases nore Experimental. In (so called) "Expectant Medicine", no sound Experience attainable but by Experiments with the Simplest Remedies.

THE highest praise which the world has to bestow upon the physician is that he is experienced. There must, therefore, be a good deal worth knowing about this experience, which is deemed his charaeteristic excellence; as, how he goes to work in search of it, and how he gains it, experimenting after his manner, and with whatever helps of science he can muster, or with none at all ; but still experimenting. For in Medicine nothing that deserves the name of expe rience can be otherwise gained than by what deserves the name of experiment.

According to the common notion, experiment is usually concerned with inert matter, or, at all events, with things which have not life. But we need not hesitate to transfer it to vital actions and processes. Medical practice satisfies the requirements of an experiment, when it puts the vital frame, with which we have to do, under conditions of our own choosing, and takes note of the results. The sum of these results becomes our experience. And this is suggestive of future experiments in eâdem materia, how best to set about them, how best to conduct them, and the fittest means and instruments to employ upon them. These experiments are, in fact, the practice of physic, perfecting itself by use, and consummated in experience. His experience is each physician's depository of whatever principles, pians, and means he possesses for executing his future experiments; his foundations to work upon, his diagrams to work by, and his tools to work with.

Now the practice of medicine, when it is engaged in treating disease, acute disease especially, comes pretty near the current idea of an experiment. There is, then, always something within view and within reach, taken for the immediate object of experiment, and so taken because it is within view and within reach. Also there is test and trial made of things one by one, and note taken of single consequences and effects as they arise under our hands, promising, promoting, and ending in the ultimate effect, which is the departure of disease and restoration to health.

But, in curing disease, the current idea of an experiment is upon the whole less apparent. The one ultimate effect is the thing contemplated, and the thing aimed at by the remedy. There are no tests or trials of things one by one preparatorily, no note of single consequences and effects intermediately. Yet, when the one $u^{l}$ timate effect is near at hand, and follows rapidly upon the use of the remedy, as does the cure of ague upon the use of quinine, then there is nothing wanting to the idea of an experiment in the completest practical sense. Thoughtful men are at liberty to penetrate deeper into the secret, and find out intermediate effects, if they can. The rest of us are content with the simple result, and can repeat it any day by the same instrumentatity. We can all cure an ague by quinine. The arrow leaves the bow and hits the mark. We see that, and we see this. But between that and this the way of the arrow was through the air, and for an instant we lost sight of it altogether.

Now if it be true in any large sense that medicine, to have sound experience for its conclusions, must have sound experiment for its practice, there should be plenty of instances at hand to prove it. And so there are. Since the least fallible of our senses has been brought to bear upon the two most vital of our organs, their diseases have come more and more within the reach of our scrutiny, and more and more within the compass of our knowledge. And so, too, has correlatively their treatment. The treatment, especially, of diseases of the lungs, both acute and chronic, can now hardly otherwise be prosecuted than as it is made to take the form of an experiment, and to comply with its conditions.

Take pneumoria, acute pneumonia. It tells itself articulately to the ear. The ear follows it as it advances and as it recedes, and the ear dwells upon it as it stands still. Not that pneumonia can syllable its own name, and so tell us what it is. But its living facts speak audibly for themselves; and they are the disease, be they few or many, very few or very many; and these same are the objects of remedial experiment. But mind, there are other objects which are mixed with them and come first in experimertal order.

There are troubled states of the vascular system, and the nervous system, which are, as it were the body's signals of distress. Some intimate one thing, and some another. Certain of them bid us specially beware that somewhere within the man there may be inflammation going on. And, then, forthwith we betake ourselves to search for it in any part which falls under our suspicion, by whatever means we can. And thus finding, wherever it be, any unwonted organic movements, such as have part and place in inflammation, forming or formed or progressive, any that lie in the way by which it travels to its well known events, then we take the same, and, be they few or many, we call them inflammation, and we treat them accordingly.

Thus a portion of the lung, crackling as it breathes, this is pneumonia ; a portion crackling as it breathes and another portion giving no sound at all, these are pneumonia; portions crackling and portions silent, and, moreover, the bronchial breathing and the bronchial voice, these are pneumonia. And all these, as they shift and change, and precede and succeed, and variously intermingle with one another, do much more than by themselves singly or collectively, stamp and constitute the disease pneumonia.

Now our treatment takes up pneumonia as it finds it, early or late, and represented by few or by many of its living facts. But this treatment has two aspects. Indeed, I am not refining, being quite sure that, if it lose its simplicity, our treatment is spoilt as an experiment altogether. It has, 
I say, two aspects, and complies with the conditions of an experiment in both. One aspect is turned towards the lungs themselves; the other looks elseThere, and almost everywhere, in the body beyond the lungs.

Not from the lungs themselves, nor from the living facts now at work within them, or their number, or their combinations, or their changes, as noted and measured by the ear, does the treatment of pneumonia take its beginning and make choice of its remedies, and apply them with force, great or small; but from the vascular system and the nervous system, and from the present condition of both, as they are taken to mean strength or weakness, reaction or surrender, and all their degrees of much or little, rapid or slow, as noted and interpreted by what the pulse has to tell of them from day to day, or from hour to hour.

This is one aspect of the treatment; and experimental enough it is !

But all the while, and from first to last, the treatment is turned to the lungs, where it finds the aim of all, and the end of all. Here it metes out what it has to do, and then what it has done; and here it again and again metes out what still remains for it to do, and at length it makes its final reckoning of perfect or imperfect reparation. This is the treatment's other aspect! And in this, too, it is experimental enough. And truly, whenever pneumonia is very acute, and the living facts within the lungs are undergoing changes from day to day, and even from hour to hour, and whenever the remedies employed are capable of making a like rapid impression counteractively, then the physician, if he is to proceed safely and successfully, must work his treatment, as he would work an experiment, with his finger upon the pulse and his ear upon the chest, from day to day or even from hour to hour.

Strange enough, perhaps, it may seem to some, that I should find an example of treatment shifting and variable, and curiously experimental, according to the needs of particular cases in that very disease, where braver spirits have made boast of a treatment simple and uniform, and comprehensive of all cases, and to be settled beforehand. Men have held that the proper treatment of pneumonia is by depletion, always and absolutely, and so have bled in every case ; and men have held that its treatment is by stimulation, always and absolutely, and so have given wine or brandy in every case. But if there be truth in the principles which have been laid down, the unconditional adrocates of either extreme are hopelessly wrong-headed. Nay, should any believe in a golden mean, equidistant from both extremes, and pretend that they know it and can practise by it always and absolutely, the experimental necessities of every case they treat should convict them of folly.

I have purposely dwelt upon this instance of pneumonia and its treatment, believing it to contain a great practical lesson. When disease is very acute, and its work of injury and disorganisation makes very brief stay in one stage and then advances to another, and each stage is fairly denoted to the watchfulness of the physician, and restoration to health and soundness are yet within reach' of treatment, that treatment must be conducted strictly as an experiment from day to day or from hour to hour.

But a large share of what is justly deemed the experience of physicians, is conversant with results brought about by what, in any popular sense, would hardly be called experiments. Reparation of the disease, indeed, takes place, not without our interposition, or without means of our choosing, or without the witness of our senses. But then the amount, and the times, and the occasions of interference on our part are less, and fewer than seem naturally annexed to the business and working of experiments.

After a fair examination of their disease and its conditions, and the choice made of some fit place to dwell in, and some cautions given against what is wrong, and recommendations of what is right in diet and modes of living, how many patients are left to nature to do all the rest, and never seen more by the physician! Or seen again after long times, once or twice or thrice, and fairly examined again and again, and the same advice reiterated, or new cautions and recommendations given, according to altered conditions, the patients are remanded to nature as before! And thus, after the lapse of months or years, even many months or many years, nature has done her work faithfully and well. She has restored to health from various forms of chronic disease. Or, without perfect reparation, she has brought even incurable disease to one of those pauses, now understood by physicians, which are sure and lasting, and consistent with a long and an useful, and, allowing for human changes and chances, a happy life.

Physicians, the older they are, come to reckon a large amount of this sort of experience; and, in the meantime, they may seem more like men waiting for results than procuring them, more as if passively looking on than busied with experiments.

But, experiment or no experiment, call it what you will (and one would not willingly press a word into our service to distort the sense), yet if there be a choice and use of means with a view to certain effects, and those effects be appreciable and actually appreciated from time to time, however slow may be their progress and remote their accomplishment, something tentative and in the way of trial has been going on all the while. And who were its institutors and promoters? Even ourselves. We chose the means, and set them to work, and still continued them at work from observations, made at needful intervals, that the work was proceeding slowly and surely towards its accomplishment. And thus, and thus only, do physicians gain whatever experience they have in the management of many chronic diseases. And, though not exactly in the popular sense, yet in a just and true sense, this experience is the sum and complement of experiments; equally so with their experience in the management of acute diseases.

Take, for illustration, the commonest of diseases with which we have to do-a disease of the lungs too, and eminently chronic, even consumption. What was the state of the lungs when our patient went a certain winter to Madeira, and what when he came back? What was it during the next summer, when he remained at home? What when he again went to Madeira, and what when he again returned home, and what after he had remained at home a second summer? Here the treatment of the disease is brought plainly within the category of experiment. It is ruled for years by the double experiment of the good and evil of climate in individual cases. 
There is no disease of which the treatment is so simply and delicately experimental as pulmonary consumption. Its success (within all possible limits of success) depends upon keeping it experimental through its whole course ; and in particular cases it is best secured when the treatment is allowed to rest from first to last in the same hands. I am quite sure that its failure in an infinite number of cases has been owing to their passing from one physician to another. Let the general experience and practical skill of the several physicians be equal, and equal too the interest they take in the well-being of their patient; yet every time he passes from one physician's hands to another's, the probability of his recovery is seriously diminished. The reason is this : the treatment thus runs the chance of often halting and often beginning afresh-of being taken up by one, not at the same point where it was left by another, or not with the same views; in short, the chance of being utterly spoiled as an experiment.

Nothing less than this could be fairly said of the treatment of phthisis, if it were a disease always of a certain type, transacting itself in its own way, and admitting no foreign admixtures. But there are in phthisis the accidents of the disease (its separable accidents, you may please to call them. They are scarcely separable, however, but in idea). There is hardly a case in which some or other of them are not present; and, being present, they bear practically upon the treatment according to their kind and degree, and never fail to bring it more and more within the category of an experiment. Thus from time to time, and under stress of its accidents, will phthisis become practically an acute disease.

Inflammation is an accident of phthisis. More than an accident, according to some, who would hold a measure of inflammation needed to help and hand it on from stage to stage. However this may be, enough of it is doubtless sometimes present to require the treatment of inflammation for a little season, in order to save the patient's life.

Hæmoptysis is an accident of phthisis. No fact, which is not of the essence of the disease, occurs more frequently. And it is never a barren accident; it always means something. And, as its meanings are various, so is its treatment, which takes the form of a carefully conducted experiment in every case.

Much employed physicians are never without many cases of phthisis under their care which are to them objects of interest and experiment, at different stages, for years. And their retrospect of twenty or thirty years, read by the needful records they have kept of their experimental treatment, brings forth an experience which is beyond all price.

Surely, for us physicians, it is not a vain exercise thus to run over what knowledge we have of two diseases common enough, yet very portentous, and try it and test it by its uses; to take pneumonia and phthisis, and their living facts, ordinary and extraordinary, and seek in them notices of times and opportunities and warrants of what to do and what to abstain from doing; and so to gain for the treatment of particular cases the condition of exact experiments. Instances of other diseases might be added, but let these be enough.

And these great experiments, and such as they, make up a great experience. And the experience thus made is rich and prompt and clear in devising and working out other future experiments ; and both together stand for nothing less than the active power and truth and faith of practical medicine.

The end of all the thought and labour of physicians is to make experiments with men's lives. Then what mischances, misjudgments, misinformation, what fallacies of all kinds, are apt to interfere with these experiments, and hinder or mar them! And then how difficult to assign them a place and a value among the materials of a sound experience! We study and pore over the essential constituents of diseases, and learn where to look for indications of their treatment. We wait and watch for the customary accidents of diseases, and learn how to encounter them. Precepts, books, authority, which is the experience of other men, serve us for great helps. But, when the cases come, their treatment must be specially and individually our own experiment, and our own hands must have the doing of it.

Excellent things have been spoken of Experience and of its great value to the physician. And justly. But, then, men are apt to talk largely and at random about what they are agreed to praise. And they have so talked about the Experience of physicians. Report would make it a very common thing indeed; as if all who had been in the way of it could not miss of possessing it. But the having to do with diseases and remedies for thirty or forty years does of necessity no more make men experienced physicians, than looking upon the heavens all their lives makes them astronomers, or digging and delving the earth makes them geologists.

It is a divine aphorism (all know whence it comes) that "Patience worketh experience." It is both divine and true; true of all good things, from the least and lowest to the greatest and highest. And surely what belongs to man's mortal life, and the physician's care concerning it, reaches no mean degree in the general scale of all good things.

It is expedient that medical practice should in every case be conformed to the current idea of an experiment as far as the nature of that case will admit. No Experience worthy of the name can be drawn from any number of cases less accurately followed up than they might have been. In acute cases, when the rate of progress in the disease is rapid yet distinct; so distinct that it can be measured by steps and stages from day to day or from hour to hour, care must be taken that the counteractive impression of the remedies be rapid, and distinct withal; to be seen from day to day or from hour to hour. And to such cases, and to their remedies thus chosen and applied, and to their effects thus noted and appreciated, no one can deny the nature of experiments, and not allow that the sum of such experiments may stand for a safe Experience.

But when the rate of progress in the disease is by little and little, and upon the whole so slow that it can only be seen after the lapse of weeks or months, then the counteractive impression of remedies must needs be also by little and little and slow, and incapable of being seen and measured except after the lapse of weeks or months. The remoteness of the effect is the condition which especially tends to perplex the procedure, and make void the results of each case as it occurs, and take from it the character of an experiment.

The power of medicine over chronic diseases is a thing hard to get at and appreciate justly. Never. 
theless, there is some sound experience of it in the world. And this could only be so far as, in our dealings with particular cases, we have been able to make them read to us the lessons of so many real experiments. Experiments they must be in some sort, if they are to furnish the materials of Experience.

But, in medical practice, as the one ultimate effect is more and more distant in point of time, and little or nothing is to be seen, or contrived; or done preparatorily and intermediately, the current idea of an experiment becomes obscured or well-nigh lost.

It is like a man travelling to some far off place, and finding no places by the way where he can sit down and rest himself, and few or no guide-posts to tell him whether he be in the right direction for it or not. Still he holds on. Perhaps he has been there before, and is pretty sure of this being the direction in which he found it. Or, perhaps, he has never been there, but some of his friends have, and they told him of this being the right road to it. And so it may be that, by his own sagacity and the help of well-informed friends, he reaches it at last. Or, after all his own pains, and all his friends can do for him, it may be that he never reaches it at all.

This parable fairly sets forth the sort of Experience which the physician is obliged to content himself with, in seeking whatever good his art can reach within a large field of practice. It is an Experience of summary and ultimate results, !with little or no insight or reckoning had of prior and conducive events. It is a general Experience made up of what a man knows himself, and what he takes upon authority. In this field of practice, it is hard to believe ourselves exercising the same experimental art, as when every step we took was made almost sure to us, and we could almost read and analyse the disease by its remedies as we went along.

But there is what is called "expectant medicine." It points to a more cultivated field of practice than that which we have been just surveying. The term is significant, and implies the attitude of expectation which the mind now maintains; waiting upon its own self-experience, and still waiting in faith of (what it deems) trustworthy authority, for a more or less distant event. Now, a rare enough thing to meet with among physicians is this wisely expectant mind. It presumes a study and sound judgment of the sort and measure of evidence which the subject admits, and a decision habitually exercised upon it; not demanding more, but never content with less.

But there is a scepticism common among us, and much fostered by the philosophical part of our training, which is hostile to this state of mind. It requires evidence foreign to the subject-matter or more than it admits of ; and so not finding it, it believes in nothing.

Again, there is a credulity common enough among us ; and this is in sympathy with the larger credulity of the world on medical subjects, and is strengthened by it. It incapacitates for all patient inquiry ; and it may come to believe in everything. Now, if there be no mean between the extremes of scepticism on the one hand, and credulity on the other, there can be no safe and successful practice in this region of "expectant medicine." But such a mean there is, in which all good physicians meet, and communicate, and understand one another, agreeing together in that prudent, patient, hopeful faith which they all perceive, but none can define.

Yet, when we come to test the matter fairly, how can there be any experience in this field of " expectant medicine?" For how can the management of individual cases of most chronic diseases, whether by cure or treatment, be conformed to the idea of an experiment? Verily, to any great degree of perfection, neither one nor the other is possible. But even in "expectant medicine" experiment would be practicable, and experience attainable in much higher degrees than they are, if physicians would only be content to work with fewer and simpler remedies.

I have myself a reasonable amount of faith in the power of medicine over chronic diseases. I have laid up a certain sum of experience fairly collected (as I believe) from experiments which I have been making all my life. But, then, all my life, I have been careful about my experiments, in this respect especially, I have sought to manage my cases of chronic diseases-in other words, to work my experiments-as much as possible by single remedies. On any other terms, I do not see how it were possible that I should have any faith at all. It is a mystery to me how such prescriptions as the following for any known forms of disease can end in any trustworthy experience :
Quinine
Steel
Zinc
Valerian
Ipecacuanha
Stramonium
Colchicum
Nux vomica
Iodide of potassium

Such complex prescriptions render the knowledge of the remedial effects of particular substances absolutely impossible. Do the prescribers impute a distinct effect of its own to each of the ingredients, and so reckon the separate instalment brought by each to the remedial mass? Or are they content to take it in the lump, and rejoice in the oneness of the effect?

My excellent friend Dr. Chambers, as soon as he had chosen medicine for his profession, did not think it beneath his dignity to work at a great pharmaceutical chemist's, compounding medicines and making up prescriptions. Here he saw what had been carefully preserved, the autograph prescriptions of bygone physicians. And those which bore the initials of the most eminent were remarkable for these two characteristics, their plain and legible penmanship, and the very few and simple articles which they directed. Surely, it is not unsafe to read the men's minds in these documents, and conceive the character of their thoughts and proceedings in the great business of their lives. The men were evidently candid and clear-sighted and of simple purpose ; and among them were the best of their timeDr. Heberden, Sir George Baker, the elder Dr. Warren, Dr. David Pitcairn, and Dr. Baillie. In our day, the profession of medicine needs a little gentle pressure from some such hands as these, to steady it and keep it within bounds.

A gentleman went from Scotland to consult a celebrated watering-place physician. His complaint was asthma. A scheme of diet was laid down for him, scrupulously and minutely strict; and he followed it to the letter. A mixed multitude of medicines was prescribed for him, which had an unpromising look of strife and incongruity. But he 
took them all bravely and obediently. And verily he had his reward. He obtained relief of his asthma. But the asthma would still return ; and, as often as it returned, he betook himself to his dietetic and remedial discipline, and it went away again; and so his faith was confirmed. In process of time, however, whether the diet was too austere or the medicine too nauseous, and so the flesh began to rebel, or whether a laudable curiosity set him to find ont the secret of his treatment and relief, he certainly began to question the necessity of all the means to the end. So, on his next attack, adhering to his dietetic rules, he bravely took no physic. But the asthma abided, and would not leave him until he had recourse to his accustomed medicines. On the following attack, he set at nought his dietetic rules, and scrupulously took his physic; and the asthma passed away as usual.

It was pretty plain that the physic-bottle contained the cure. But to which of the many ingredients did it belong? To one or two or three, or to the whole hotch-potch working mysteriously together for good? In a matter which so nearly concerned him, the patient might be pardoned for laying his rash analytical hands upon the mysterious mixture. It contained, among twenty other things, a few grains of iodide of potassium. Ingredient after ingredient was deducted; and, simpler and simpler as the mixture became, it still had equal power to abate the asthma, until the iodiàe of potassium was deducted in its turn, and then its sovereign power was gone. Again, all the ingredients were tried, excepting only the iodide of potassium; but altogether they did not touch the asthma remedially. Finally, every other ingredient was excluded, and the iodide left alone; and alone it displayed a sovereign remedial power.

Fortunate the man who can get rid of an asthmatic attack on any terms; but unfortunate the art that is content with a rare fortuitous and unaccountable success; it must be either retrograde or stationary. To scatter above twenty remedies, and to let hit which may, is like pigeon-shooting in companies. The bird falls ; but whose gun was it that brought it down? Nobody is reputed the better marksman after a hundred volleys.

With all the credit due to pharmaceutical chemistry, and all our obligations to it, I doubt whether, in one chief respect, it has not done some harm. To bring many important remedies together, and unite them by a lucky combination, and compress them within a small compass, and so place them within the common reach, all this gives a facility of prescribing which is hurtful to the advance of medical experience. The facility of prescribing is a temptation to prescribe; and, under this temptation, there is a lavish expenditure continually going on of important remedies in the mass, of which the prescribers have made no sufficient experiment in detail. A simple implement or two, which a man has well proved for himself, is worth a whole armoury of famous compounds taken upon the general credit. A few thousand years ago, a whole people was in fear and trembling. Their enemy was at the gate. Their hope was turned to a single champion. All weapons of war were at his service. The king's own armour was offered him-his helmet, his coat of mail, his sword. He did not (how could he ?) resist the vanity of putting them on. But soon he put them off again; for "he had not proved them". And "he chose him five smooth stones out of the brook", and with one of these he did the deed which saved his country.

\section{glluxstrations}

\section{OF HOSPITAL PRACTICE: METROPOLITAN AND PROVINOIAL.}

\section{MEDICAL COLLEGE HOSPITAL, CALCUTTA.}

\section{IODIDE OF POTASSIOM IN THE TREATMENT}

OF ANEORISM.

By S. G. Chuckerbutty, M.D.

WHEN I took charge of my duties as second physician to the Medical College Hospital, in August 1860, among the patients there was one of the name of Leary, who had been under treatment for some time for a pulmonary complaint. He was an Irish seaman, rather short, tolerably stout, and about fifty years of age. In addition to a harassing cough and profuse expectoration, he had at this time a pulsating tumour in the upper notch of the sternum, of about the size of a walnut, but elastic, and readily emptied by pressure. This tumour grew gradually larger and larger, and rose higher in the neck, until it was nearly as big as a small orange, en. croaching somewhat on the median line. A great variety of medicines had been used for the cough, without any influence on the aneurismal tumour, until I prescribed iodide of potassium with decoction of cinchona. Soon after this, it became evident that not only was his cough benefited by the change, but the aneurism also grew harder and heavier, and lost its expansile character. The man was ultimately carried off about the beginning of January 1861, by a fresh attack of bronchitis.

At the post mortem examination, on opening the chest, we found an aneurismal tumour lying immediately behind the upper part of the sternum, and rising in the neck as far as the junction of the trachea with the larynx on the right side. It sprang from the inner aspect of the innominate artery, and did not involve either the aortic arch or the right subclavian or carotid arteries. It was very heavy, and as large as a pear. Its in. terior was occupied by a compact mass of solid coagula, leaving merely a small channel at the outer aspect, through which the right carotid and subclavian arterieg communicated with the arch of the aorta; a piece of whalebone introduced into either of these vessels pass. ing into the latter. The lining membrane of the bronchial tubes in both lungs was highly vascular, thickened, and occupied by un abundant secretion.

While the above patient was still alive, there were admitted into my wards two other Europeans-Bateman and Collyer-both suffering from aortic aneurism. These two men had been given a variety of sedatives and astringents, without relief, prior to the employment of iodide of potassium ; which, in sooth, I did not order for them until I saw its beneficial effect in the case of Leary. The result proved as satisfactory as in the first case, as far as the solidification of the aneurismal sac was concerned, though it did not prevent a fatal issue.

Bateman was admitted into the hospital on November 30 th, 1860, from the ship Newcastle, with the following history from the surgeon on board.

"Jobn Bateman, aged 47 , by profession a sailor, of sanguineous temperament, has sailed mostly to tropical climates, been a hard spirit.drinker, never suffered from rheumatism, and has always enjoyed good health until 